\title{
A site assessment of pavement cracking in a drought environment: a case history
}

\author{
James B. Nevels, Jr. ${ }^{1, a}$, Christopher R. Clarke ${ }^{2}$, Lizhou Chen ${ }^{3}$, and Rifat Bulut ${ }^{4}$ \\ ${ }^{1}$ Geotechnical Engineering Consultant, Norman, Oklahoma, USA \\ ${ }^{2}$ Geotechnical Engineer, Oklahoma Department of Transportation, Oklahoma City, Oklahoma, USA \\ ${ }^{3}$ Graduate Student, Oklahoma State University, Stillwater, Oklahoma, USA \\ ${ }^{4}$ Associate Professor, Oklahoma State University, Stillwater, Oklahoma, USA
}

\begin{abstract}
This paper builds upon the findings of a site investigation into the causes of longitudinal cracks that developed soon after the re-construction of Himes and Johnson Streets in the City of Norman, Oklahoma between May to September 2012. The re-construction of the city street pavement and base course were completed during a protracted drought period, and shortly after completion of the pavement section longitudinal cracks occurred predominantly along the curb line. The case history concluded that the drought conditions resulted in significant subgrade soil shrinkage. The shrinkage caused changes in soil suction with depth resulting in tensile stresses in the asphalt pavement and stabilized subbase that lead to the pavement cracking. A simple practical moisture/suction variation model with depth (Hamberg) was used in conjunction with the soil water characteristic curve (SWCC) to make predictions of the soil suction changes that are resulting in the pavement cracking. The paper documents the comparison of the Hamberg model used in the case history with the Mitchell and finite element (FEM) models. The purpose of the comparison was to see if improved accuracy of the Mitchell model and a finite element model resulted in significant changes in the prediction of soil suction.
\end{abstract}

\section{Introduction}

In a recent case history involving longitudinal cracks that developed in two re-constructed city streets within weeks following the completion of the paving and opening up to traffic, a forensic study was performed to explain the causes for the cracking. The question was asked by the City of Norman of the project geotechnical engineer, Burgess Engineering and Testing, Inc. (BETI), to explain why the newly constructed pavements developed predominantly longitudinal cracks within weeks following completion of the paving. A compounding factor in this forensic study was the fact that the (BETI) geotechnical engineer requested that the explanation of the longitudinal cracking be done with minimum of testing and cost. This request necessitated the use of estimated soil properties. Documentation of the case history is presented by Clarke, Nevels, and Cabrera [1].

\section{Pavement typical section}

The street construction required the removal of the old $150-\mathrm{mm}$ concrete slab pavement installed in the early 1950 's. The new pavement section consisted of $150-\mathrm{mm}$ asphalt pavement placed in two lifts (bottom 100-mm layer and a top $50-\mathrm{mm}$ layer) underlain by a $150-\mathrm{mm}$ thick hydrated lime modified subgrade base course.
During and following the pavement re-construction in the spring and summer of 2012, the asphalt separated from both integral mountable concrete curbs throughout the lengths of the pavement re-construction for both Himes and Johnston Streets. The crack widths were observed to range from a 3 to $13 \mathrm{~mm}$. Additionally, longitudinal cracks were also seen to develop under the canopies of the larger trees and in a few non-tree areas.

At the time of the re-construction of Himes and Johnson Streets, the City of Norman as well as much of Oklahoma experienced a very dry year. A snap-shot of the climatic conditions for approximately one year period from the time of the project letting forward based on the Standard Precipitation Index (SPI) ranged from a moderate to an extreme drought.

\section{Subgrade characterization}

According to the current US Department of Agriculture (USDA) Natural Resources Conservation Service (NRCS) [2], the predominantly mapped soil series underlying the lineal extents of both Himes and Johnson Streets is the Kirkland soil series, 0 to 3 percent slopes. The soil profile presented in Figure 1 was used in the subgrade analysis to characterize the Kirkland soil profile with depth. An estimate of the shrinkage limit with depth was made from Arthur Casagrande equation, Shrinkage

\footnotetext{
$\overline{{ }^{a} \text { Corresponding author: jnevels1@ }}$ cox.net
} 
Limit $(\mathrm{SL})=20+/-\Delta$ pi, where $\Delta$ pi is the distance above or below the A-line in the soil plasticity chart [3]. The dry unit weight $\left(\gamma_{d}\right)$ was estimated from the tabulated primary characterization data found in the Web Soil Survey for selected Kirkland soil series pedons in Cleveland County wide basis [4]. The soil properties in the (NRCS) data set that matched the depths of the hand auger boring shown in Figure 1 was selected for the subgrade soil analysis. The total unit weight $\left(\gamma_{t}\right)$ and shrinkage limit (SL) estimates are shown in Table 1. The specific gravity of the Kirkland soil series soil with depth was estimated as 2.70 .

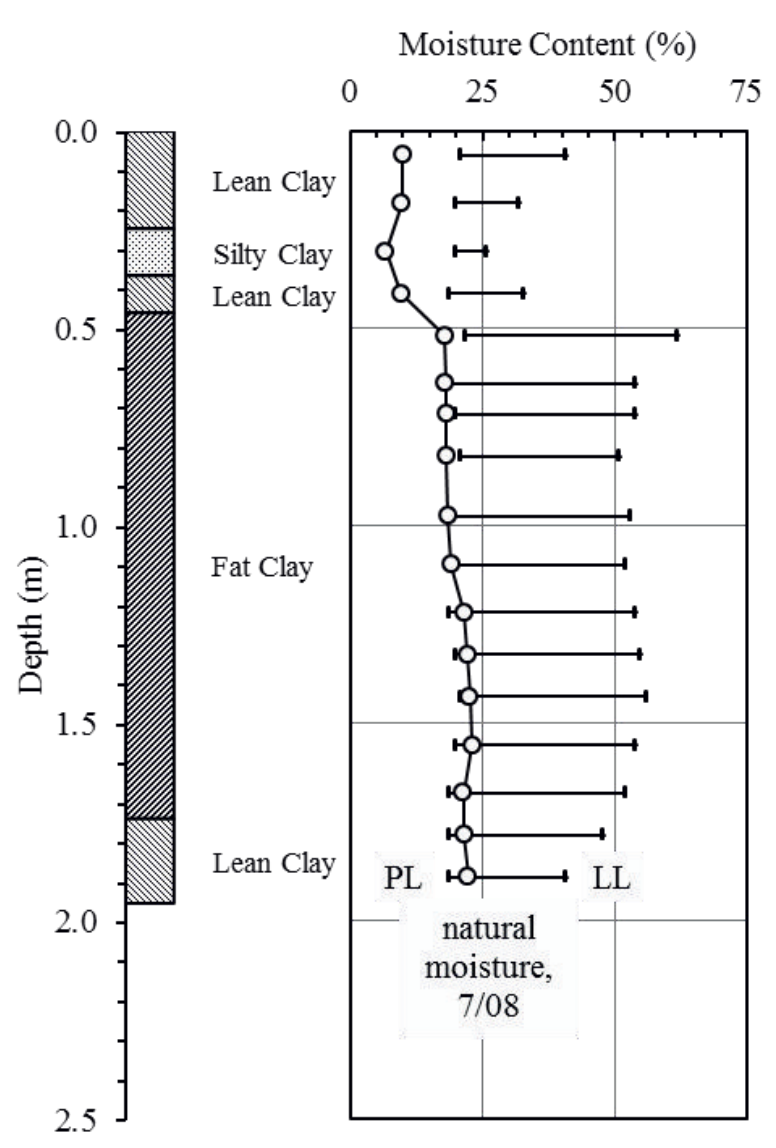

Figure 1. Kirkland series profile giving gravimetric moisture content versus depth.

The in situ moisture contents used in the analysis were taken from an average of the four auger borings in the BETI report. These auger borings were augured to a depth of $0.91 \mathrm{~m}$. The four gravimetric moisture content (MC) measurements were all made in the subgrade soils at 0.30 - and $0.76-\mathrm{m}$ depths on Himes and Johnson Streets, and these moisture contents were at or exceeded the plastic limit. The average moisture content at the 0.30 - and $0.76-\mathrm{m}$ depths respectively were used the wet side points in the analysis of the Kirkland soil profile in Figure 2.

\section{Hamberg moisture variation model}

The problem encountered in the case history is one where the effect of drought drying conditions can be evaluated on an exposed subgrade where the initial moisture content is at approximately the plastic limit near the ground surface (following pavement removal) and approaches the shrinkage limit an extremely dry soil profile prior to paving.

Table 1. Kirkland soil series shrinkage limit estimate.

\begin{tabular}{|c|c|c|c|c|c|}
\hline Horizon & $\begin{array}{l}\text { Depth } \\
\text { (m) }\end{array}$ & $\begin{array}{c}\gamma_{\mathrm{d}} \\
\left(\mathrm{kg} / \mathrm{m}^{3}\right)\end{array}$ & $\begin{array}{l}\text { MC } \\
\text { (\%) }\end{array}$ & $\begin{array}{c}\gamma_{\mathrm{t}} \\
\left(\mathbf{k g} / \mathrm{m}^{3}\right)\end{array}$ & $\begin{array}{l}\text { SL } \\
(\%)\end{array}$ \\
\hline Ap1 & $\begin{array}{l}0.00- \\
0.12\end{array}$ & 1710 & 9.99 & 1880 & $*$ \\
\hline Ap2 & $\begin{array}{l}0.12- \\
0.27\end{array}$ & 1640 & 9.77 & 1800 & $*$ \\
\hline Bt1 & $\begin{array}{l}0.27- \\
0.37\end{array}$ & 1690 & 6.73 & 1800 & $*$ \\
\hline $\mathrm{Bt} 2$ & $\begin{array}{c}0.37- \\
0.51\end{array}$ & 1860 & 9.68 & 2040 & 13 \\
\hline Bt3 & $\begin{array}{l}0.51- \\
0.67\end{array}$ & 1800 & 18.07 & 2130 & 10 \\
\hline Bt4 & $\begin{array}{l}0.67- \\
0.85\end{array}$ & 1940 & 18.13 & 2290 & 11 \\
\hline Btk1 & $\begin{array}{l}0.85- \\
1.17\end{array}$ & 1660 & 18.78 & 1970 & 12 \\
\hline Btk2 & $\begin{array}{l}1.17- \\
1.44\end{array}$ & 1880 & 22.08 & 2300 & 11 \\
\hline Btk3 & $\begin{array}{l}1.44- \\
1.74\end{array}$ & 1800 & 23.06 & 2220 & 11 \\
\hline Btk4 & $\begin{array}{l}1.74- \\
2.04\end{array}$ & 1930 & 22.37 & 2360 & 13 \\
\hline Btk5 & $\begin{array}{l}2.04- \\
2.38\end{array}$ & 1760 & 24.75 & 2200 & 14 \\
\hline
\end{tabular}

* Profile was excavated to $0.4 \mathrm{~m}$. In Table $1, \mathrm{MC}$ is the gravimetric water content and SL is the shrinkage limit.

Estimates of idealized of initial and final moisture contents/suction in the soil profile are required in order to predict the effect of the drought climatic conditions had in causing the pavement cracking. The Hamberg model [5] which is based on the assumptions that the initial moisture content near the ground surface does not fall much below the shrinkage limit and the maximum moisture content under a paved surface does not significantly exceed the plastic limit was utilized in the analysis. Choosing the plastic limit and the shrinkage limit as the initial and final moisture contents, respectively allows for a straight line assumption between the ground surface and the active depth, see Figure 2 . The average moisture contents at the 0.30 - and $0.76-\mathrm{m}$ depths from the BETI report respectively were used the wet side points in the analysis of the Kirkland soil profile in Figure 2.

\section{Suction comparison using different methods}

It is well established in the literature that suction change is a primary reason leading to the development of longitudinal cracks in pavements. Based on the measured 
moisture contents at different depths, the suction can be obtained using different methods. In this section, the suction profile from soil water characteristic curve (SWCC) will be compared to the suction profile from Mitchell model and FEM analysis respectively.

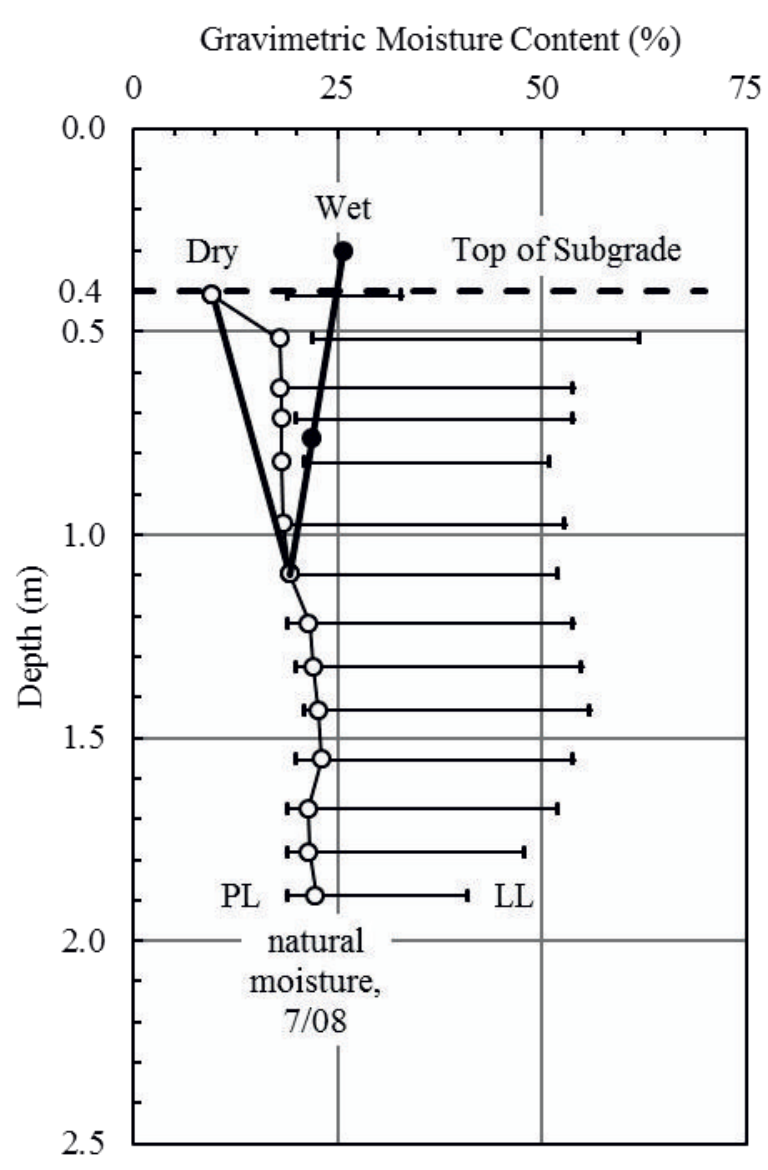

Figure 2. Kirkland series gravimetric moisture content profile.

\subsection{Suction profile from SWCC}

Zapata [6] proposed that the fitting parameters of Fredlund and Xing model [7] were closely related to the plasticity index and the percentage passing No. 200 sieve for plastic soils. The following equations were put forward to calculate those fitting parameters:

$$
\begin{gathered}
a_{f}=0.00364(w P I)^{3.35}+4(w P I)+11 \\
m_{f}=0.0514(w P I)^{0.465}+0.5 \\
n_{f}=m_{f}\left[-2.313(w P I)^{0.14}+5\right] \\
h_{r}=a_{f}\left[32.44 e^{0.0186(w P I)}\right]
\end{gathered}
$$

where $e$ is Euler's number (2.71828), wPI is the product of plasticity index and decimal passing No. 200.

For Kirkland soils, the average product of plasticity index and percentages passing No. 200 sieve is 33.47 . Substituting those values into Equation (1), (2), (3) and (4), the four fitting parameters obtained are: $a_{f}=611, m_{f}$ $=0.76, n_{f}=0.93$, and $h_{r}=36945$. The saturated gravimetric moisture content is 0.25 . Equation (5) is obtained by substituting the data above into the model of Fredlund and Xing [7]. Figure 3 is the soil water characteristic curve (SWCC) generated using Equation (5):

$$
M C=\left\{1-\frac{\ln \left(1+\frac{\psi}{h_{r}}\right)}{\ln \left[1+\left(\frac{10^{6}}{h_{r}}\right)\right]}\right\}\left\{\frac{M C_{s}}{\left[\ln \left(e+\left(\frac{\psi}{a_{f}}\right)^{n_{f}}\right)\right]^{m_{f}}}\right\}
$$

where, $M C$ is the gravimetric water content, $M C_{s}$ is the saturated gravimetric water content, $\psi$ is the suction, and $a_{f}, m_{f}, n_{f}$, and $h_{r}$ are the curve-fitting parameters.

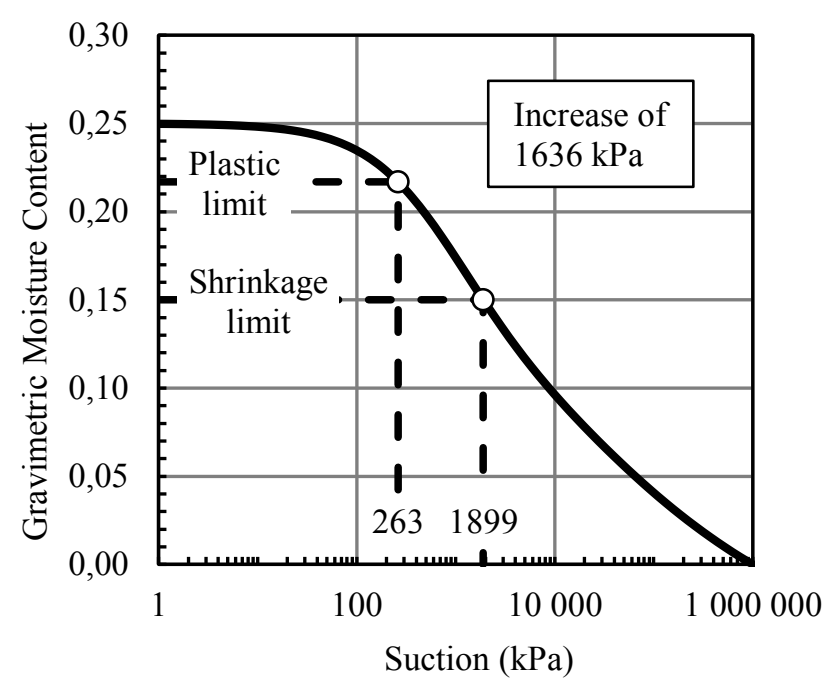

Figure 3. Kirkland series soil water characteristic curve (SWCC).

In this analysis, the equilibrium moisture content is equal to plastic limit (i.e., 18.13\%), the moisture content at the dry side and wet side are $15.00 \%$ (i.e., shrinkage limit) and $21.68 \%$, respectively. Substituting those values into Equation (5), the suction is obtained, and it is 812.8 $\mathrm{kPa}$ at equilibrium state, $1905.5 \mathrm{kPa}$ at the dry side, and $263.0 \mathrm{kPa}$ at the wet side. It is noted that the SWCC is generated using the boundary gravimetric water contents predicted by the Hamberg model, which is utilized in comparing the results with the Mitchell and FEM models as described below.

\subsection{Suction profile from Mitchell model}

Another widely used model for predicting suction profile is Mitchell's model [8]. The governing differential equation is given by Equation (6), and described in detail in Lytton et al. [9]. Mitchell solved the partial differential Equation (6) when the soil is subjected to a constant suction at the surface of subgrade, and the solution for these boundary conditions is provided in Equation (7):

$$
\begin{gathered}
\frac{\partial u}{\partial t}=\alpha \frac{\partial^{2} u}{\partial x^{2}} \\
u=u_{0}+\left(u_{f}-u_{0}\right)\left(1-\operatorname{erf} \frac{x}{2 \sqrt{\alpha t}}\right)
\end{gathered}
$$


where, $u$ is the suction, $t$ is the time, $x$ is the depth, and $\alpha$ is the diffusion coefficient, $u_{0}$ is the initial equilibrium suction, $u_{f}$ is the final surface suction, and the term "erf" is the error function.

In order to make a reasonable comparison between the Mitchell and Hamberg (based on SWCC), it is assumed that their initial suctions and final surface suctions are the same. Also, the drying time (time from when the subgrade was exposed to the atmosphere until the subgrade was paved) is 3 months, and the diffusion coefficient is $1.0 \times 10^{-1} \mathrm{~mm} / \mathrm{s}$, which is a typical value of diffusion coefficient of soils in Oklahoma. The diffusion coefficient is a back-calculation in the model to fit active depth and the moisture content limits at the surface.

\subsection{Suction profile from finite element analysis}

Besides the Hamberg and Mitchell models, a numerical method (FEM) is also utilized to study the change of suction with depth. Due to the similarity between suction diffusion and heat diffusion, the "Heat Transfer Model" in Abaqus software is utilized for analyzing the distribution of suction in subgrade soils.

In this analysis, the final surface suction, the equilibrium suction, the drying time and the diffusion coefficients are the same as those used in the Mitchell and Hamberg models. The boundaries of the FEM model are shown in Figure 4(a). The CD side is the surface of subgrade soil which is exposed to constant suctions. AB side is the bottom of subgrade, and regarded as no suction change, and $\mathrm{BC}$ side and $\mathrm{AD}$ side are the vertical boundaries of the subgrade soil. Figure $4(\mathrm{~b})$ is the screenshot of dry suction profile obtained from Abaqus. The red color means the highest suction $1905.5 \mathrm{kPa}$, and the blue color represent the equilibrium suction 812.30 $\mathrm{kPa}$, and the other colors are for transitional suctions. The suction profiles predicted by the three models are presented in Figure 5.

\subsection{Comparisons}

Figure 5 is generated using the suctions from SWCC (using the Hamberg model), Mitchell model and finite element analysis. It can be seen that the shapes of the suction profiles predicted by the Mitchell and FEM models are similar, as compared to the Hamberg model.

Suction decreases with depth on the dry side, and increases with depth on the wet side. Also, all curves intersect at $1.0-\mathrm{m}$ depth, which is the depth of the moisture active zone. Meanwhile, it is found that the suction envelope predicted by the Hamberg (SWCC) is significantly larger than the suction envelopes predicted by Mitchell and FEM models, especially on the dry side as compared to the wet side of the suction envelopes.

Although the governing differential equation for moisture flow for both the Mitchell and FEM models is the same, there are some differences between them, especially at shallow depths. Even though the Hamberg model is very simple and practical to use, one should be cautious in terms of its validity for realistic prediction of suction profiles. On the other hand, the Hamberg model can be accurate enough to generate the suction profile on the wet side for practical purposes.

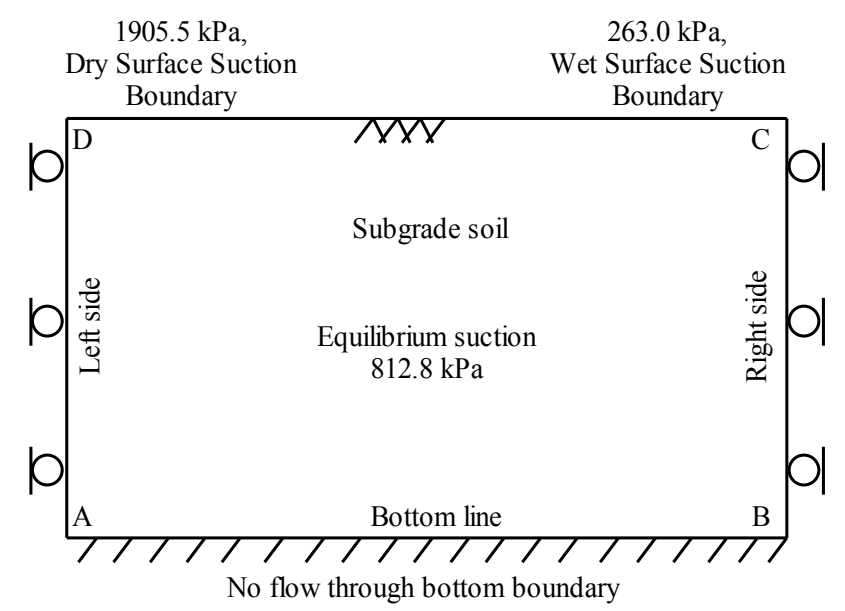

(a)

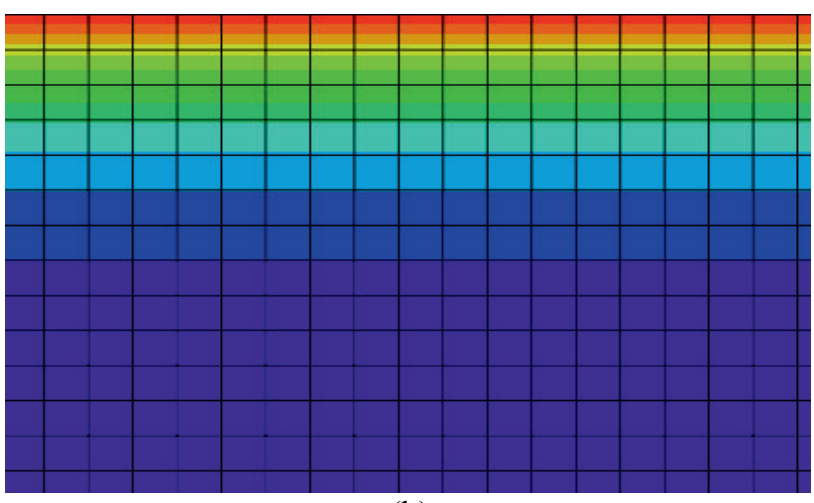

(b)

Figure 4. (a) Geometrical model of FEM; (b) Distribution of suction with depth at dry side.

\section{Conclusions}

The SWCC provides an expedient way of relating moisture/soil suction with depth for a soil profile. The data presented is in terms of soil suction for the case history where a pavement was removed with the underlying subgrade soil moisture at or exceeding the plastic limit and allowed to dry out to approximately the shrinkage limit before the pavement was laid. Based on the data presented in the three models in Figure 5, the following conclusions can be made:

- The Mitchell and FEM analysis predict similar estimates of the soil suction with depth. The Mitchell and FEM models are very close on the wet side but diverge slightly more with depth on the dry side.

- Integrating the area between the wet and dry curves for each model in Figure 5, the areas between the subgrade surface and the active depth are as follows: $\mathrm{FEM}=414 \mathrm{kPa} \cdot \mathrm{m} ;$ Mitchell $=482 \mathrm{kPa} \cdot \mathrm{m}$; and Hamberg $=827 \mathrm{kPa} \cdot \mathrm{m}$. On a ratio basis and assuming that the FEM provides the best estimate with depth at 1.0, the Mitchell has a ratio of 1.16, and the Hamberg model has a ratio of 2.00 . 
- The variation in the model curves is consistent with published field data in the dry side versus wet side moisture content/suction profiles with depth.

- Regarding the prediction of moisture content/suction with depth, the Hamberg model is a good first indicator but very conservative approach considering especially the dry side.

- The Hamberg model is appropriate only for preliminary analysis.

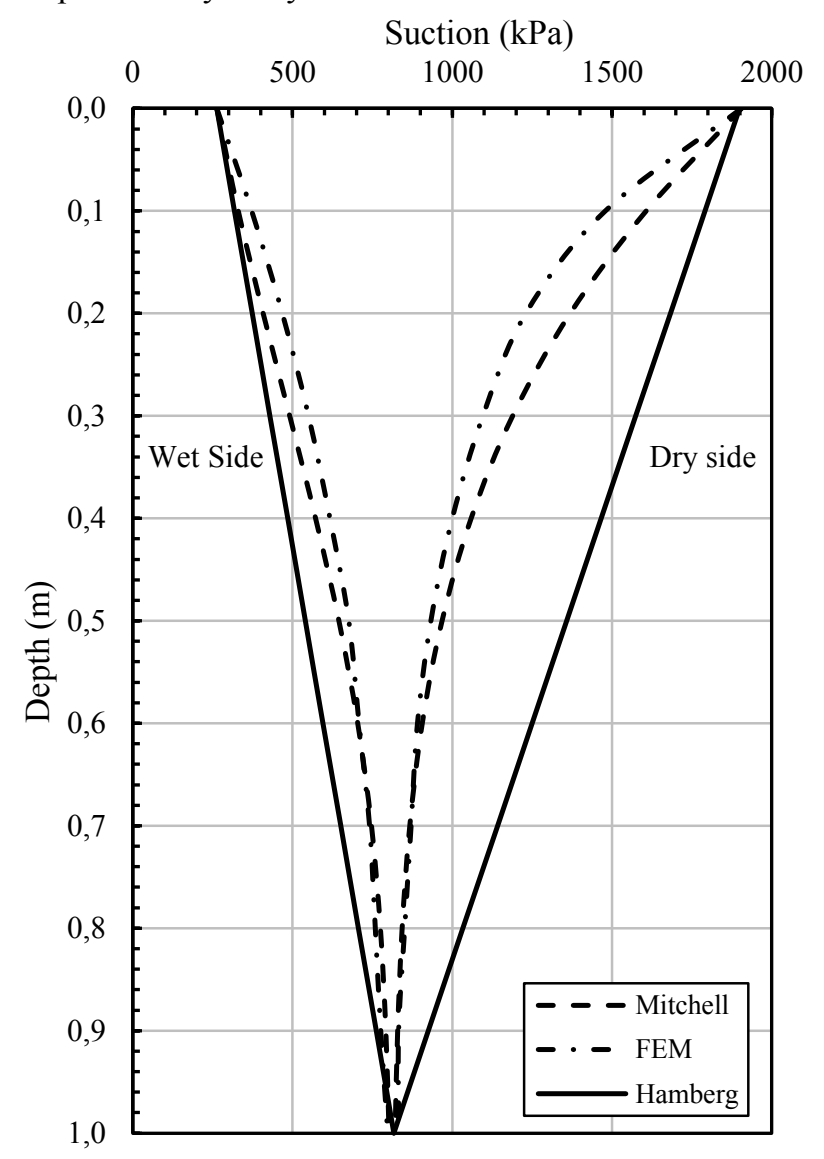

Figure 5. Comparison of suction profiles from different models.

\section{References}

1. C.R. Clarke, J.B. Nevels, Jr., A.S. Cabrera, "Himes and Johnson Street Subgrade Soil Analysis", UNSAT2014, Sydney, Australia (2014)

2. Natural Resources Conservation Service (NRCS), Web Soil Survey 3.1, Washington, DC: US Department of Agriculture (2014)

3. R.D. Holtz, W.D. Kovacs, An Introduction to Geotechnical Engineering (Prentice-Hall, Inc., Englewood Cliff, NJ, 1981)

4. Soil Conservation Service (SCS), Soil Survey of Cleveland County, Oklahoma. Washington DC: US Department of Agriculture (1987)

5. J.D. Nelson, D.J. Miller, Expansive Soils: Problems and Practice (John Wiley \& Sons, Inc., New York, 1992)

6. C.E. Zapata, "Uncertainty in soil-water-characteristic curve and impacts on unsaturated shear strength predictions." Ph.D. Dissertation, Arizona State University (1999)

7. D.G. Fredlund, A. Xing, "Equations for the Soil-Water Characteristic Curve", Canadian Geotechnical Journal, 31(3): pp. 521-532 (1994)

8. P.W. Mitchell, "The structural analysis of footings on expansive soil." Research Report No.1, Kenneth W.G Smith and Associates Pty. Ltd. Newton, South Australia (1979)

9. R.L. Lytton, C.P. Aubeny, R. Bulut, "Design procedure for pavements on expansive soils." TxDOT Report No. 0-4518-1, Texas Transportation Institute, College Station (2005) 